about that region. The metamorphosis accompanying this woman's recovery after her first illness was very extraordinary if not inexplicable.

In conclusion, I would say that to presuppose such a discovery after death as has been described would raise expectations of other than mere pressure symptoms on the branch of the third nerve supplying the levator palpebræ superioris muscle. Why this, and this alone, was implicated was, though sought for, not made out.

Brighton.

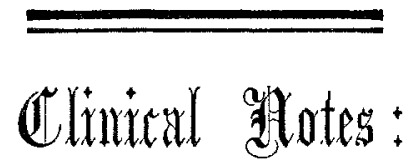

MEDICAL, SURGICAL, OBSTETRICAL, AND THERAPEUTICAL.

\section{NOTE ON A CASE OF NEEDLE-POINT IN THE FINGER FOR NINE MONTHS;} RADIOGRAPH.

BY W. H. Coates, M.B. DURH., M.R.C.S. EnG., L.R.C.P. LOND., \&c., BARRISTER-AT-LAW.

A GlRL, aged 16 years, was washing a floor on Dec. 4th, 1898, when she felt a pricking feeling in her finger. During the ensuing fortnight two small pieces of needle came out at the dorsal surface of the right middle finger about the junction of the matrix of the nail with the finger. The pieces were one-quarter and one-eighth of an inch in length respectively. The finger after a lapse of a month became inflamed, and on Feb. 4th, 1899, she came to me for the first time. I removed a needle-point a quarter of an inch long from the ulnar side of the second phalanx of the middle finger. The girl complained constantly of a pricking feeling and inability to use the finger afterwards, so another incision was made, and a second point was removed from the same place, of a slightly less length than the first. The finger was dressed with airol and it rapidly healed, but the patient still complained of the inability to use the member, and of an occasional feeling of a sharp pain if it were pressed. The nail of the finger had in the meantime been shed. As I had removed two needle-points I ridiculed the idea of the possibility of another needle-point in the finger, and as there was certainly no external mark whereby an entrance had been made and on the most careful and repeated examinations I was unable to feel or detect in any way the presence of any foreign body, I felt certain that the patient must have imagined it although she was not neurotic or hysterical in the slightest degree. Six months passed away during which inquiries were made by me from time to time, but always with the same answer that the finger was numb and not so useful as heretofore. On August 24th she was sent to Messrs. Reynolds and Branson of Leeds to have a radiograph taken. This successfully showed the needle which was three-eighths of an inch long and was situated actually on the dorsal surface of the bone. On Sept. 11th a deep incision was made and the needle was removed at once. The whole of the three points were blackened.

Hull.

\section{A CASE OF SNAKE-BITE TREATED WITH CALMETTE'S ANTIVENENE SERUM ; RECOVERY.}

BY S. J. RENNIE, L.R.C.P. EDIN., M.R.C.S. ENG., MAJOR, ROYAL ARMY MEDICAI CORPS.

A HINDU BOY, aged 12 years, was brought to me at about 9 P.M. on July 10 th with typical symptoms of snake-bite in its most pronounced form. The history of the case was that the boy was lying asleep on the ground when he felt something bite him on the little finger of the left hand. Being very drowsy he merely shook off the offender and went to sleep again. He was, however, shortly wakened by great pain in the arm and shoulder, which were seen to be much swollen and discoloured. This was soon followed by vertigo and blindness, and he sank into a lethargic condition, in which state he first came under my notice. On examination two small punctured wounds were seen over the first phalanx of the little finger of the left hand, evidently inflicted by a snake of some 12 to 18 inches in length-probably the dreaded "krait" (Bungarus cæruleus). The left arm, the left chest, and the face were found to be swollen and odematous ; the eyelalls protruded, with ptosis of both lids. Deglutition was difficult, respiration was laboured, and frothy blood-stained sputum was oozing from between the lips. Blood-stained mucus was also exuding from the rectum. There was complete paralysis of the whole of the left side of the body. The heart's action was irregular and intermittent. I at once injected 12 cubic centimetres of Calmette's antivenene hypodermically and gave a beef-tea and brandy enema. Whilst the enema was being given the breathing, which had gradually been getting more difficult owing to the paralysis of the respiratory muscles, ceased altogether. The heart's beats were only four per minute, each beat getting more feeble. Artificial respiration was now commenced and was carried on for 20 minutes, by which time the serum had done its work and the patient had regained power over bis respiratory muscles. From this time onward be steadily recovered and in five days was practically convalescent, the symptoms disappearing in the inverse order of their onset. One curious point was that for some 10 days subsequently the patient had diplopia in the left eye (the side he was bitten on), but this also ultimately vanished and he is now as well as ever he was in his life.

The value of Calmette's antivenene serum as a specific in cases of snake-bite has now been so fully proved by experiment in the laboratory and also in many instances in actual practice since the first case treated by me in India some three years ago, that no special advocacy of its claims is necessary. There are, however, two points worthy of note in the foregoing record. One is the proof that the remedy may be employed with every hope of success even in the most extreme cases, and the other is that the serum will retain its properties for an indefinite period in any climate, as the antivenene used had been in my possession in the plains of India for nearly four years.

Meerut, North-West Provinces, India.

\section{NOTE ON A TWISTED PEDICLE.}

By A. C. Butler-Smythe, F.R.C.P., F.R.C.S. Edir.

IN May, 1895, a woman, aged 50 years, was admitted into the Samaritan Free Hospital for Women under my care. She had an abdominal tumour and was emaciating rapidly. On examination a large moveable swelling was found somewhat inclined to the left of the middle line and reaching to the umbilicus. On its left side there was a protuberance easily definable through the abdominal wall. Per vaginam the lower part of the growth could not be made out even on firm pressure from above. I asked my senior colleague (Dr. Bantock) to see the patient with me, and he was struck with the extreme mobility of the tumour and also with the fact that it could not be felt from the vagina. He pointed out, however, that the protruding lump was on the right side of the swelling and not on the left as I had stated. Next day I examined the patient again and found the protuberance in its original position on the left side of the tumour and was satisfied that some mistake had been made as to the exact location of the irregular portion of the growth. Two days later the patient told me that she had had a sore, dragging sort of pain in the left side for some hours, but it was not bad enough to complain of at the time. On palpating her abdomen the swelling was found to be much altered in shape, and the protuberance could not be felt on either side. Per vaginam, the base of the tumour was well down in the pelvis and bimanually fluctuation could easily be detected. The uterus was behind the cyst and was freely moveable. Whilst examining the patient I purposely pushed the tumour up out of the pelvis and almost immediately the outline of the protuberance appeared on ber right side and moved quickly across her abdomen to the left iliac region. I made a note of the occurrence, and whilst thinking the matter over, the patient's abdomen being uncovered and she lying on her back, I was surprised to see the "protuberance" wandering slowly back across the abdomen from left to right. 